\title{
Paramagnetic Ions Affect Relaxation Rate Dispersion of Blood: Implications for Magnetic Resonance Relaxation Dispersion Imaging
}

\author{
Bertil R.R. Persson ${ }^{1 *}$, Lars Malmgren ${ }^{1,2}$ and Leif G. Salford ${ }^{3}$
}

${ }^{1}$ Medical Radiation Physics, Lund University, Lund Sweden

${ }^{2}$ MAX Laboratory, Lund University, Lund Sweden

${ }^{3}$ Department of Neurosurgery, Lund University, Lund Sweden

\begin{abstract}
The proton relaxation rate dispersion of paramagnetic ions in blood samples was studied in the frequency interval from $10 \mathrm{kHz}$ to $10 \mathrm{MHz}$. With the Field cycling method we applied, the samples were first magnetized by a relatively high magnetic field $(0.5 \mathrm{~T})$. By electronic means this field was rapidly $(1 \mathrm{~ms})$ reduced to a lower value in the interval 0.1 $\mathrm{mT}-0.5 \mathrm{~T}$, where the excited proton spin may relax during a time interval of about 3.T1max. Then the magnetic field is again quickly raised up to the higher level for the detection of the NMR-signal. The relaxation characteristics were analyzed by applying a model with three compartments of water proton-spin exchange. For each compartment we estimated a correlation frequency by fitting the dispersion curves to a sum of Lorentz distributions. We found that low concentrations of paramagnetic ions have a large influence on the relaxation rate dispersion in the low frequency region $<10 \mathrm{MHz}$. This effect is suggested to be used for mapping of inorganic paramagnetic or organic free-radical compounds in medical applications as contrast agents and for tracing cellular activity by subtracting MR images recorded at high $(>100 \mathrm{mT})$ and low $(<10 \mathrm{mT})$ relaxation fields. Such sequences of images could be used to study the oxygen status and metabolism of the brain as well as the generation and distribution of reactive oxygen species (ROS). This technique called "Magnetic resonance Relaxation Dispersion Imaging" (MARDI) would be particularly suitable to analyze various neurological diseases such as stroke, MS, Alzheimer's disease as well as brain tumor progression. It might also be suitable for imaging of tumour oxygenation and in vivo ROS distributions in radiation therapy, which could be used in dose planning and for analyzing and optimizing the effect of various radiation therapy regimes.
\end{abstract}

Keywords: Field-cycling; MARDI; MRI; NMR; Relaxationdispersion; Imaging; Paramagnetic

Abbreviations: MARDI: Magnetic resonance Relaxation Dispersion Imaging; MRI: Magnetic Resonance Imaging

\section{Introduction}

Magnetic Resonance Imaging (MRI) is primarily based on local variations of proton relaxation rate, caused by the interaction of water molecules with tissue proteins, lipid membranes and other tissue components. Paramagnetic ions $\left(\mathrm{Mn}^{2+}, \mathrm{Gd}^{3+}, \mathrm{Fe}^{2+} / \mathrm{Fe}^{3+}\right)$ and organic radicals have a great influence on the relaxation rate and can be used as contrast agents and for tracing cellular activity. The change in relaxation rate between oxygenized and deoxygenized blood was displayed already in 1982 on the front-page of one of the first textbooks on medical applications of NMR imaging, although in Swedish [1]. That MR-image was recorded at December 15 in 1981 at Aberdeen University, with one of the first NMR-imaging devices [2-3]. It is apparent that the difference in relaxation rate between oxygenized and deoxygenized blood arises from the difference in relaxation rate between $\mathrm{Fe}^{3+}$ and $\mathrm{Fe}^{2+}[4]$. The experimental ratio of the relaxation rate $\left(1 / T_{1}\right)$ for $\mathrm{Fe}^{3+}$ versus $\mathrm{Fe}^{2+}$ is about 18.2 in aqueous environment.But in agarose gels which should mimic tissue it is decreased to about 7.64 [5].

Already in the early 1980-ies we started to study the relaxation properties of different brain tissues in order to understand the basics of the NMR-imaging technique. We found that brain tissues in vitro are characterized by a wide range of proton relaxation rates $\left(1 / T_{1}\right)[6-$ 17]. We also studied the use of super-paramagnetic particles as contrast agents in T2 NMR-imaging of the liver in rats [14].

In the present investigation we have studied the relaxation rate dispersion of blood in the frequency region $0.01-10 \mathrm{MHz}$ by cycling the relaxation magnetic field in the range of $0.234-234 \mathrm{mT}$ [18-19]. In the field cycling NMR spectrometer we used, the sample is first magnetized in a relatively high magnetic field $(0.5 \mathrm{~T})$, which then by electronic means rapidly $\left(10^{-3} \mathrm{~s}\right)$ is reduced to a lower value where the excited proton spin may relax during a time interval about $3 \cdot \mathrm{T} 1_{\max }$ Then the magnetic field is again quickly raised up to higher level for the detection of the NMR-signal. This procedure is repeated with stepwise varying the relaxation field in the range of $0.2-240 \mathrm{mT}$ to create a dispersion curve [20].

Various molecular theories are presented for explaining the shape of the relaxation dispersion in tissue. We apply a model, which relates to exchange of intermediary bound water protons that gradually transfer their magnetization to bulk water protons [21-23]. The relevant frequency range for such relaxation dispersion is determined by the dynamics of the molecular processes.

In the frequency region from $10 \mathrm{kHz}$ to about $10 \mathrm{MHz}$ the proton relaxation rate is related the exchange of spin of bound water molecules with the bulk water. In the present investigation we study the influence of paramagnetic Mn-ions on the relaxation rate dispersion in this frequency region. By using this approach we aim to develop imaging techniques and further improve the clinical use of relaxation dispersion

*Corresponding author: Bertil R.R. Persson,Lund University, Department of medical radiation physics, Barngatan 2, S-22185, Lund Sweden, Tel: 464617 3110; Fax: 464617 8540; E-mail: bertil_r.persson@med.lu.se

Received November 14, 2011; Accepted December 12, 2011; Published December 13, 2011

Citation: Persson BRR, Malmgren L, Salford LG (2012) Paramagnetic lons Affect Relaxation Rate Dispersion of Blood: Implications for Magnetic Resonance Relaxation Dispersion Imaging. J Bioengineer \& Biomedical Sci 2:105. doi:10.4172/2155-9538.1000105

Copyright: (C) 2012 Persson BRR, et al. This is an open-access article distributed under the terms of the Creative Commons Attribution License, which permits unrestricted use, distribution, and reproduction in any medium, provided the original author and source are credited. 
Citation: Persson BRR, Malmgren L, Salford LG (2012) Paramagnetic lons Affect Relaxation Rate Dispersion of Blood: Implications for Magnetic Resonance Relaxation Dispersion Imaging. J Bioengineer \& Biomedical Sci 2:105. doi:10.4172/2155-9538.1000105

Page 2 of 8

imaging (MARDI) by using paramagnetic contrast agents. This approach is also aimed to be used to image physiological oxygenation processes in cardiac and brain imaging. Increased oxygen consumption will decrease the ratio of $\mathrm{Fe}(\mathrm{III}) / \mathrm{Fe}(\mathrm{II})$ and thus decrease the relaxation rate. But increased oxygenation will increase the $\mathrm{Fe}(\mathrm{III}) / \mathrm{Fe}(\mathrm{II})$-ratio and the relaxation-rate will increase. It will also apply to the use of spatial radiation-dose distribution imaging in ferrous-ferric gel systems [5,24].

\section{Materials and Methods}

\section{Blood sample}

Whole blood and blood plasma, which were too old to be clinically used, was donated by the blood-bank at Lund University hospital.

\section{Field cycling spectrometry}

We used a unique NMR spectrometer "Spin Master FFC" developed by Stelar [25]. The instrument is designed to measure the field dependence of NMR spin-lattice relaxation time T1 dispersion from earth field to a maximum operating field of $20 \mathrm{MHz}$. The characteristics of the spectrometer are given in Table 1.

The operating magnetic field sequence for $\mathrm{T} 1$ measurements is shown in Figure 1 [26]. Before the polarization of the sample during $\mathrm{D} 2$ there is a pre-scan delay $\mathrm{RD}$ and a pre-condition relaxation field $\mathrm{D} 1$ $=\left(4 \mathrm{~T} 1_{\max }-\tau\right)$, where $\tau$ is the time period $\mathrm{D} 4=3 \cdot \mathrm{T} 1_{\max }$ of the relaxation field. During the "STIM" period the acquisition of the NMR signal takes place after a $90^{\circ}$ RF-pulse.

\section{Evaluation of the proton-spin relaxation-rate dispersion}

The recorded proton-spin relaxation rate dispersion curves are fitted to Lorentz frequency distribution curves according to the following model:

\begin{tabular}{|l|l|}
\hline $\begin{array}{l}\text { FFC spectrometer } \\
\text { Component }\end{array}$ & Characteristics \\
\hline Power Supply: & $\begin{array}{l}\text { Max I }=330 \mathrm{~A} \\
\text { Max B0 }=0.5 \mathrm{~T}(23.7 \mathrm{MHz}) \\
\text { Max Slew Rate }=2.5 \mathrm{MHz} / \mathrm{ms}(0.4 \mathrm{~ms} / \mathrm{MHz}) \text { at } 20 \mathrm{MHz}, \\
5 \mathrm{MHz} / \mathrm{ms}(0.2 \mathrm{~ms} / \mathrm{MHz}) \text { at }<10 \mathrm{MHz}\end{array}$ \\
\hline Magnet: & $\begin{array}{l}\text { Field inhomogeneity } 200 \mathrm{ppm}(2 \mathrm{kHz}) \text { at B } \mathrm{B}_{\text {acquis }}=9.8 \mathrm{MHz} \\
\text { Temperature range } 16-65{ }^{\circ} \mathrm{C}(\text { at B }\end{array}$ relax up to $\left.20 \mathrm{MHz}\right)$
\end{tabular}

Table 1: Some SpinMaster FFC spectrometer characteristics.

$$
R 1=\alpha+\frac{2 A}{\pi} \cdot \frac{w}{4 x^{2}+w^{2}}=\alpha+\frac{2 A}{\pi} \cdot \frac{w^{-1}}{4 x^{2} / w^{2}+1}=\alpha+\frac{A}{\pi^{2}} \cdot \frac{v_{c}}{f^{2} v_{c}^{2}+1}
$$

Where,

$\mathrm{R} 1$ =the relaxation-rate $\mathrm{s}^{-1}$

$\alpha=$ the relaxation-rate of the bulk water $(f \rightarrow \infty)$

$\mathrm{A}=$ surface under the curve (power).

$\mathrm{x}=$ the angular frequency $\mathrm{x}=\omega=2 \pi \cdot f$;

$w=2 \pi \cdot \tau_{c}=2 \pi v_{c}^{-1}$

$f=$ the linear frequency $\mathrm{Hz}$

$\tau_{c}=$ the correlation time of bound water with bulk water (s) $(\mathrm{Hz})$

$v_{c}=$ the correlation frequency of bound water with the bulk water

The fitting was performed using the OriginPro 7.5 (Origin Lab Corporation, Northampton, MA 01060 USA). For non-linear fitting of

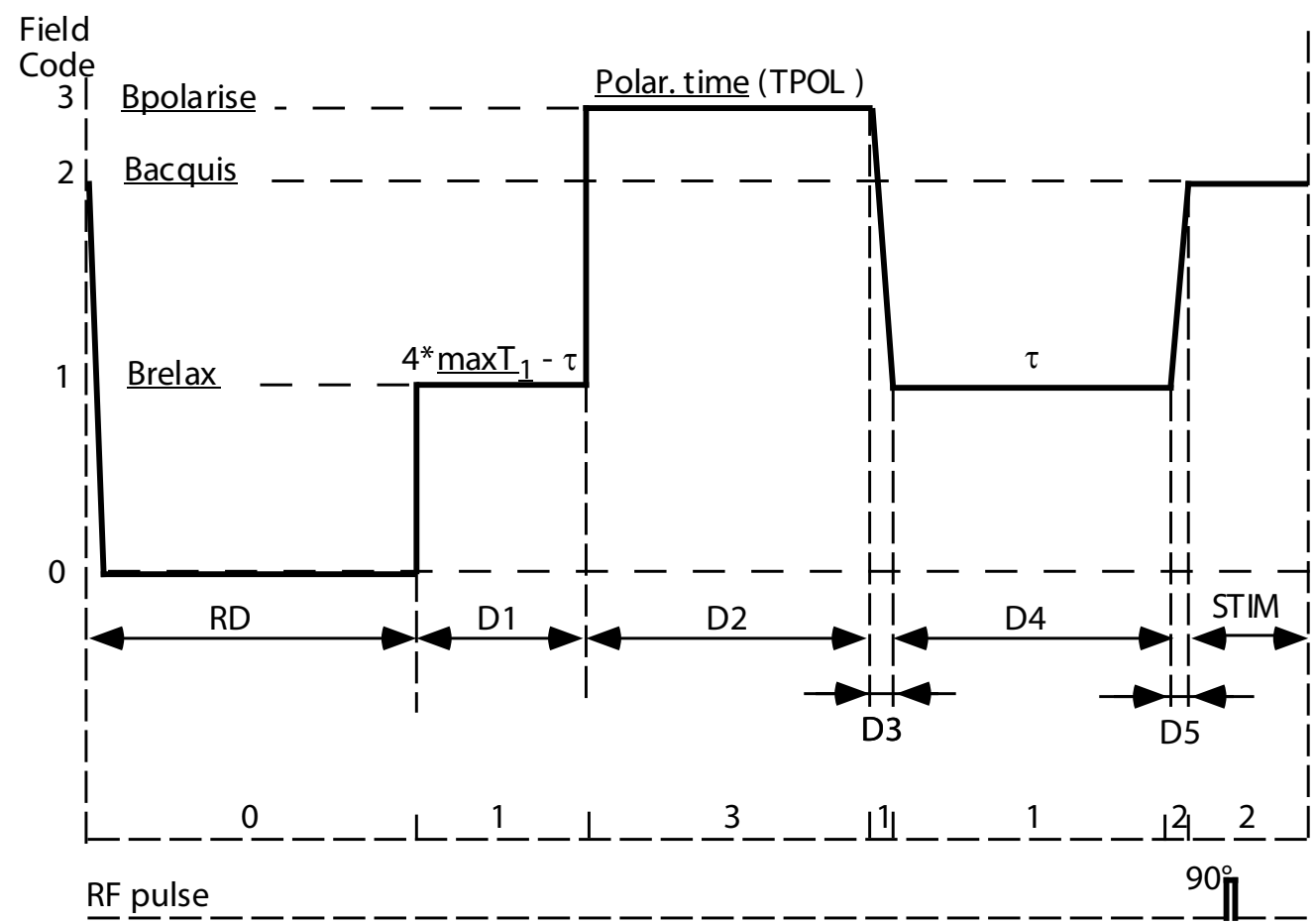

Figure 1: Balanced Pre-polarization Sequence ( PP/S ) Field cycle code: 0131122. 
Citation: Persson BRR, Malmgren L, Salford LG (2012) Paramagnetic lons Affect Relaxation Rate Dispersion of Blood: Implications for Magnetic Resonance Relaxation Dispersion Imaging. J Bioengineer \& Biomedical Sci 2:105. doi:10.4172/2155-9538.1000105

Page 3 of 8

equation (1), Origin 7.5 uses the Levenberg-Marquardt algorithm to iteratively adjust the parameters to get the minimum chi-square value. To allow better control of the iteration process, the Max Number of Iterations was set to 100 and the Tolerance to $10^{-9}$, which is used by the fitting algorithm. The program automatically gives the first initial guesses of the parameters selected for fitting. It is also possible to give the number of desired replica curves.

Linear combination of several compartments of differently bound water can be written as follows:

where:

$$
R 1(\omega)=\alpha_{\infty}+\sum_{n=1}^{N} \frac{c_{n} \cdot v_{c n}}{1+\left(f \cdot v_{c n}\right)^{2}}
$$

$\mathrm{c}_{\mathrm{n}}=\mathrm{A}_{\mathrm{n}} / \pi^{2}$ is the contribution of the $\mathrm{n}^{\text {th }}$ compartment.

The correlation frequencies, $v_{\mathrm{cn}}$ correspond to molecular compartments of water in various state of exchange equilibrium with the bulk water.

The lowest frequency $v_{\mathrm{cl}}$ corresponds to the compartment of firmly bound water molecules with longest correlation time $(\approx 30 \mu \mathrm{s})$ with bulk water.

The middle frequency $v_{c 2}$ originates from the compartment of water molecules bound in nano-cavities of macromolecules and sub-cellular units with correlation times in the order of $\approx 5 \mu \mathrm{s}$.

The highest frequency $v_{c 3}$ component is assumed to correspond to the compartment of water molecules in the hydration layer of the proteins and sub-cellular structures in the plasma, with correlation times $\approx 1 \mu \mathrm{s}$.

These correlation times are in the same order of magnitude ( 0.1 to $10 \mu \mathrm{s})$ as found by others in studies of cell water dynamics $[27,28]$.

\section{Results and Discussion}

\section{Whole blood and blood plasma}

In Figure 2 are given the NMR relaxation-rate R1 dispersion curves recorded for whole-blood and blood-plasma. The high values of whole blood at low frequencies are probably due to the presence of paramagnetic iron in the red blood cells.

The relaxation dispersion curve of blood plasma fitted to a sum of

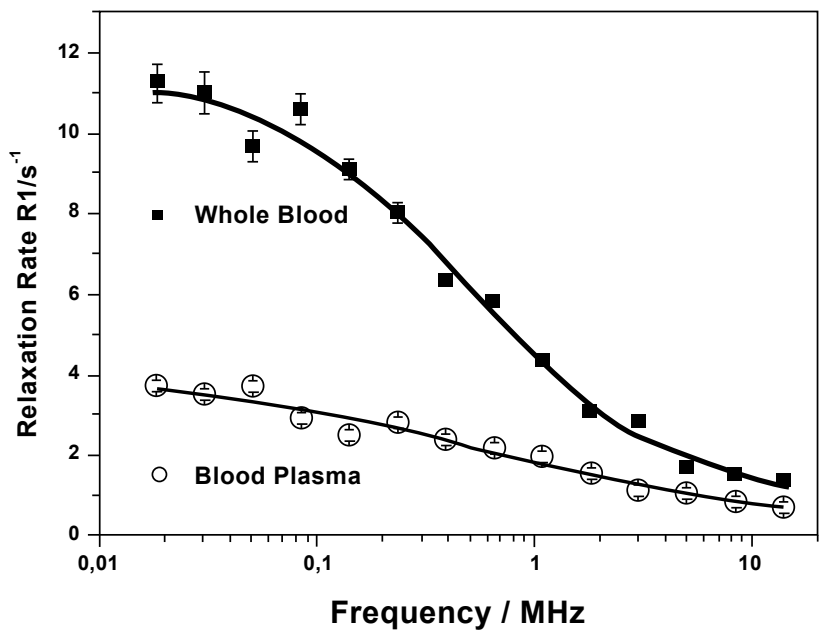

Figure 2: T1 Relaxation dispersion of fresh whole blood and blood plasma.
3 Lorentz frequency dispersion curves and the result is given in Figure 3. The correlation frequencies $v_{c}$ with free water occurred at $37 \mathrm{kHz}$, $220 \mathrm{kHz}$ and $1480 \mathrm{kHz}$, respectively. The lowest frequency is believed to correspond to the compartment of firmly covalently bound water molecules with longest correlation time $(\approx 30 \mu \mathrm{s})$ with bulk water. The middle frequency probably originates from the compartment of water molecules bound in channels and nano-cavities of macromolecules and sub-cellular units with correlation times in the order of $(\approx 5 \mu \mathrm{s})$. The highest frequency component is assumed to correspond to the compartment of water molecules of the hydration-layer of the proteins with correlation times $<\approx 1 \mu \mathrm{s})$ in the plasma.These correlation times are in the same order of magnitude $(0.1$ to $10 \mu \mathrm{s})$ as those found in studies of cell-water dynamics $[27,28]$.

The high value of relaxation rate of whole blood at low frequency

\begin{tabular}{|l|l|l|l|}
\hline Tissue & $\begin{array}{l}\text { Frequency } \\
v_{1} \text { (low) } / \mathbf{k H z}\end{array}$ & $\begin{array}{l}\text { Frequency } \\
v_{2} \text { (middle) } / \mathbf{k H z}\end{array}$ & $\begin{array}{l}\text { Frequency } \\
v_{3} \text { (High) } / \mathbf{k H z}\end{array}$ \\
\hline Whole blood & & 285 & 7600 \\
\hline Blood plasma & $37 \pm 4$ & $220 \pm 10$ & $1480 \pm 40$ \\
\hline
\end{tabular}

Table 2: Summary of the parameter obtained by fitting the dispersion curves to a sum of Lorentz distributions.

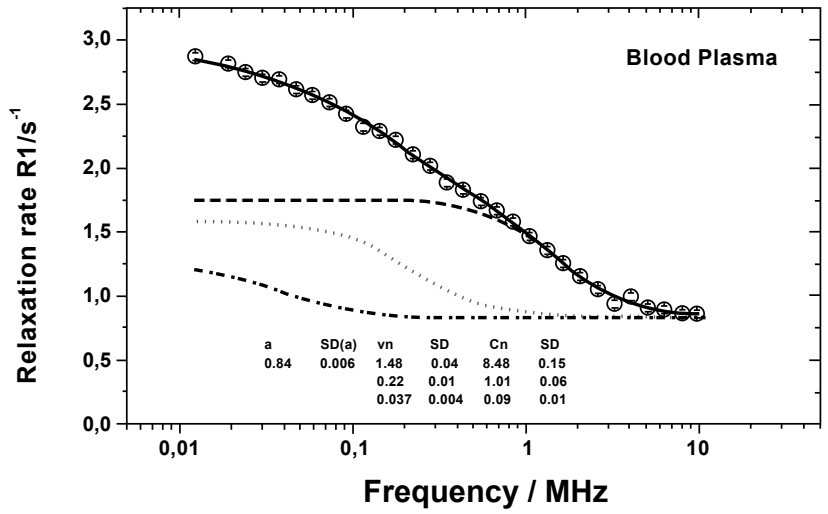

Figure 3: T1 relaxation dispersion of blood plasma modelled as a combination of 3 components with the correlation frequency components $v_{\mathrm{c} 1}$ (low) $37 \mathrm{kHz}$, $v_{\mathrm{c} 2}$ (middle) $0.22 \mathrm{MHz}$ and $v$ (High) $1.48 \mathrm{MHz}$.

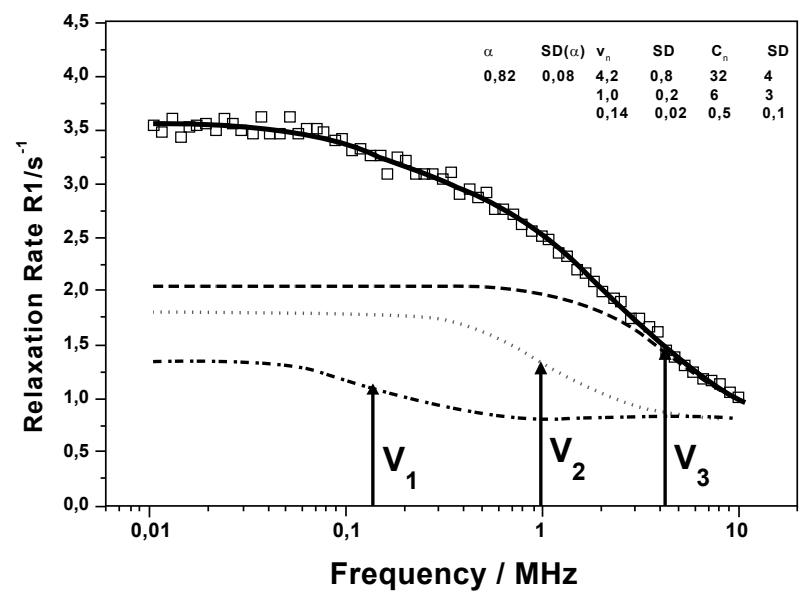

Figure 4: Relaxation rate dispersion of $0.2 \mathrm{mM} \mathrm{MnCl}_{2}$ at $\mathrm{pH}=2$. The dispersion curve is fitted to a sum of Lorentz distributions with the correlation frequency components $v_{\mathrm{c} 1}$ (low) $140 \mathrm{kHz}, v_{\mathrm{c} 2}$ (middle) $1.0 \mathrm{MHz}$ and $v$ (High) 4.2 $\mathrm{MHz}$. 
Citation: Persson BRR, Malmgren L, Salford LG (2012) Paramagnetic lons Affect Relaxation Rate Dispersion of Blood: Implications for Magnetic Resonance Relaxation Dispersion Imaging. J Bioengineer \& Biomedical Sci 2:105. doi:10.4172/2155-9538.1000105

Page 4 of 8

depends on a higher fraction of water bound in immobilized proteins and in other immobilized structures of the blood cells. The average correlation frequency is about $300 \mathrm{kHz}$. The high relaxation rate at low frequency also depends on the presence of paramagnetic iron in the red blood cells [29] Table 2 .

\section{Effect of paramagnetic ions on relaxation rate dispersion}

In the present work aqueous solutions of $\mathrm{MnCl}_{2}$ at various concentrations were used in studying the effect of paramagnetic ions in the field-cycling NMR experiments. The frequency dispersion of a 0.2 $\mathrm{mM}$ water solution of $\mathrm{MnCl}_{2}$ at $\mathrm{pH}=2$ was studied in the frequency range of $0.01-10 \mathrm{MHz}$ proton NMR frequency. The frequency dispersion curve thus obtained is shown in Figure 4. The shape of the relaxation rate dispersion curve is similar to that for protein solutions although no macromolecules are present. The following model for analyzing the various components of the dispersion curve is used:

The first compartment with lowest correlation frequency $v_{1}$ with bulk water is assumed to correspond to the inner coordination sphere of tightly bound water molecules in close contact with the odd spinning electron of the Mn-ion.

The second compartment with moderate correlation frequency $v_{2}$ with bulk water corresponds to the outer sphere with more loosely bound water molecules less accessible to the odd spinning electron of the Mn-ion.

The third compartment with high correlation frequency $v_{3}$ with bulk water is the outer hydration sphere of the $\mathrm{Mn}$-ions in direct contact with the bulk water.

The high relaxation rate at low frequency indicates that water in the inner coordination sphere is firmly bound and in close contact with the electron spin of the odd electron of the Mn-ion. The recorded relaxation rate dispersions of $\mathrm{MnCl}_{2}$ solutions at various concentrations are fitted to a single compartment Lorenz equation (4) and the data are given in Figure 5.

The relaxation rate data displayed in Figure 5 are fitted to the following single compartment Lorenz equation:

$$
R 1(\omega)=\alpha_{\infty}+\frac{c_{1} \cdot v_{c 1}}{1+\left(f \cdot v_{c 1}\right)^{2}}
$$

where:

$v_{c}=1 / \tau_{c}$ the correlation frequency $(\mathrm{Hz})$

$\alpha_{\infty} \quad=$ the relaxation rate at infinite frequency

$c_{1} \quad=$ the total contribution of bound water

$f \quad=$ Larmor frequency of protons in the relaxation B-field $(42.6 \mathrm{MHz} / \mathrm{T})$

The parameters from fitting the relaxation data to equation 3 are given in Table 3.

The relaxation rate at low $(0.02 \mathrm{MHz})$ and high $(10 \mathrm{MHz})$ frequency respectively recorded at the various concentrations displayed in Figure 6 show that the relaxation rate increases steadily with frequency for all concentrations. This makes it possibly to depict the distribution of paramagnetic ions or radical species by subtraction of images recorded at $(0.02 \mathrm{MHz})$ and high $(10 \mathrm{MHz})$ relaxation frequencies. The ratio of the relaxation rates at $(0.02 \mathrm{MHz})$ and high $(10 \mathrm{MHz})$ frequency decrease with concentration. The most optimal concentration for imaging seems to be at $\mathrm{Mn}$-concentrations in plasma below $3 \mu \mathrm{M}$.

In order to study the effect of paramagnetic ions in the presence

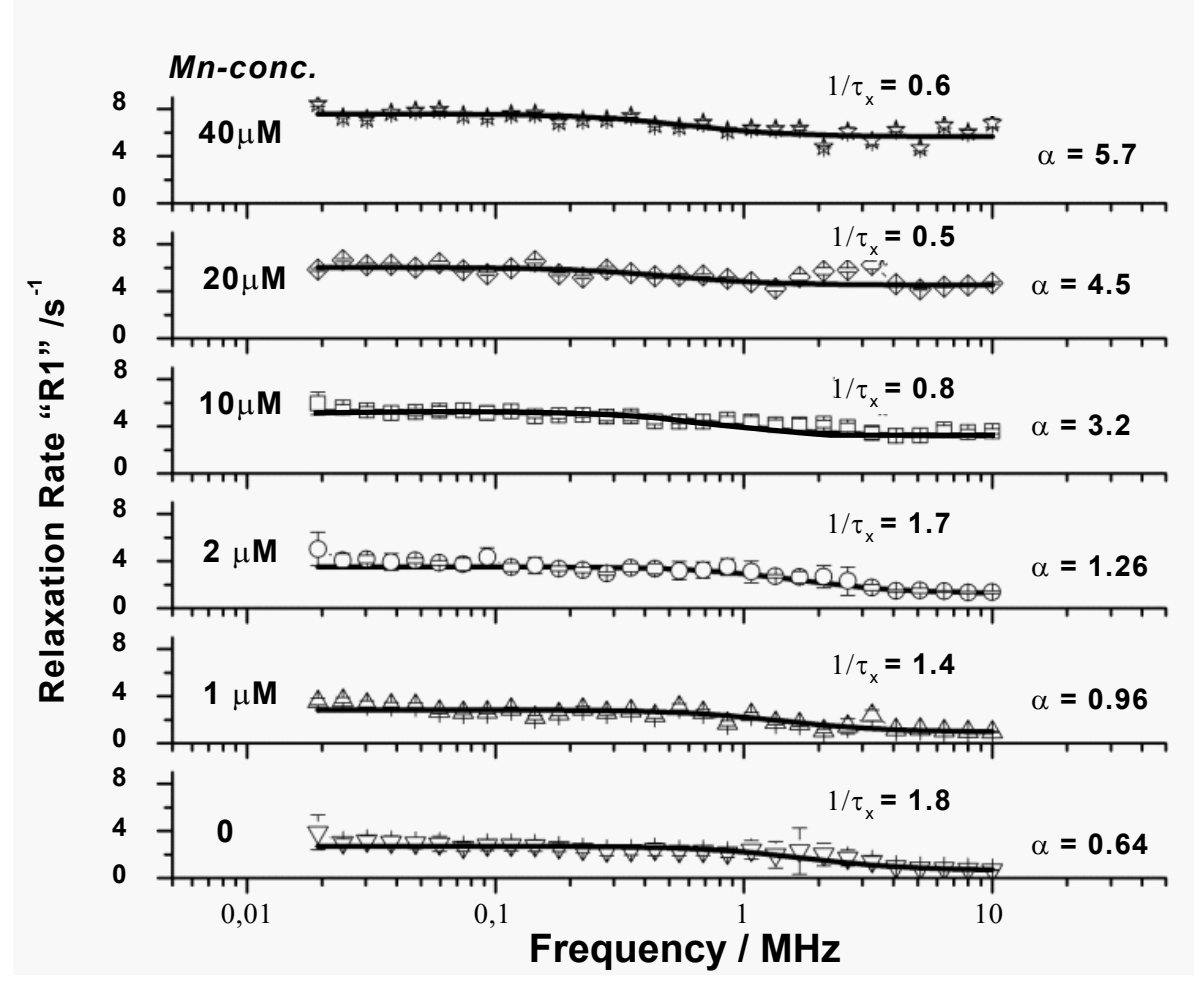

Figure 5: The relaxation rate dispersions of $\mathrm{MnCl}_{2}$ in aqueous solutions with various concentrations at $\mathrm{pH} 1$. 


\begin{tabular}{|c|c|c|c|}
\hline $\begin{array}{c}\text { Mn concentration } \mu \mathrm{M} \\
(\text { Added } \mu \mathrm{l} \mathrm{of} 0.2 \mathrm{mM} \\
\left.\mathrm{MnCl}_{2}\right)\end{array}$ & $\begin{array}{c}\text { Correlation } \\
\text { frequency } v_{\mathrm{c}} / \mathrm{MHz}\end{array}$ & $\begin{array}{c}\text { Relaxation rate } \\
\text { when } v \rightarrow \infty \mathrm{a}_{\infty} / \mathrm{s}^{-1}\end{array}$ & $\begin{array}{c}\text { Relaxation time } \\
\text { when } v \rightarrow \infty \mathrm{T} 1_{\infty} / \mathrm{ms}\end{array}$ \\
\hline 0 & 1.8 & 0.68 & 1470 \\
\hline $1(5)$ & 1.4 & 0.96 & 1041 \\
\hline $2(10)$ & 1.7 & 1.26 & 794 \\
\hline $10(50)$ & 0.8 & 3.2 & 312 \\
\hline $20(100)$ & 0.5 & 4.5 & 220 \\
\hline $40(200)$ & 0.6 & 5.7 & 175 \\
\hline
\end{tabular}

Table 3: The correlation frequency $v_{c}=1 / v$ relaxation rate at infinite frequency $\alpha$ and corresponding $\mathrm{T} 1 \infty$ relaxation times from fitting the recorded relaxation rate data to the equation (4).

of proteins, various volumes $0-5-10-50-100$ and $200 \mu \mathrm{l}$ of the $0.2 \mathrm{mM} \mathrm{MnCl}$, solutions were added to $1 \mathrm{ml}$ plasma samples under rapid stirring. Due to the irregular shape of the recorded dispersion curves displayed in Figure 7. The fitting to more than 1 replica in figure 7 resulted in overlapping curves which is present as a single curve in the figure.

Different amounts of $\mathrm{MnCl}_{2}$ added to blood plasma affected the various parameters in the relaxation rate dispersion equation (eqn. 4) as shown in Figure 8. The most evident effects appear at $\mathrm{MnCl}_{2}$ concentrations below $20 \mu \mathrm{M}$. The magnitude of the parameter $\alpha$ increase asymptoticallyup to $6.1 \mathrm{~s}^{-1}$, that corresponds to a concentration of $\mathrm{MnCl}_{2}$ of $40 \mu \mathrm{M}(200 \mu \mathrm{l})$. But the compartment of bound water and its correlation frequency seems to decrease with $\mathrm{MnCl}_{2}$ concentrations up to $20 \mu \mathrm{M}(100 \mu \mathrm{l})$. At high concentrations of $\mathrm{MnCl}_{2}$, the relaxation rate seems to increase at frequencies above $10 \mathrm{MHz}$, as seen in Figure 7. This is in agreement with the finding for relaxation enhancement of Gd-contrast agent [30].

\section{Discussion and Conclusion}

The results of the present study indicate that odd electron spin generates a high relaxation rate of proton spin at magnetic fields in the order of $0.2 \mathrm{mT}$, corresponding to Larmor frequency of about $10 \mathrm{kHz}$. The relaxation rate decreases in a sigmoidal shape at increasing field strengths up to about $234 \mathrm{mT}$ corresponding to Larmor frequency of about $10 \mathrm{MHz}$. The relaxation rates at magnetic fields above $500 \mathrm{mT}$ are rather constant and the relaxation rate correlates to the bulk water. At very low fields, however, the relaxation rate is correlated to firmly combined molecular water and thus highly influenced by the molecular electrons. The presence of unpaired electrons has a high influence upon the relaxation rate due to the large local fields they produce which give rise to their paramagnetic properties. Thus the presence of paramagnetic ions such as $\mathrm{Mn}^{2+}$ at low concentration gives rise to a much higher relaxation rate at low B fields than at high fields. A few contrast agents for MRI enhanced based on manganese are available: the liverspecific manganese(II)-dipyridoxal diphosphate (MnDPDP, Teslascan, Amersham Health) and an oral agent containing manganese(II) chloride (LumenHance). A new hydrophilic dendritic Mn(II) complex derived from diethylenetriamine pentaacetic acid (DTPA) is under consideration for brain imaging. The Mn concentrations of commonly used for MRI studies and in vivo experiments are in the order of $0.5 \mathrm{mmol}$ per $\mathrm{kg}$ [31]. Thus by using much lower concentration of paramagnetic contrast agents the paramagnetic effect would be visualized by subtracting images recorded at high $(>200 \mathrm{mT})$ and low $(0.2-10 \mathrm{mT})$ relaxation fields.

We propose a field cycle imaging technique by subtraction of an image first recorded at a pre-magnetization high field about $0.2-0.5 \mathrm{~T}$ (corresponding to proton Larmor frequencies in the range of $\approx 9-21$

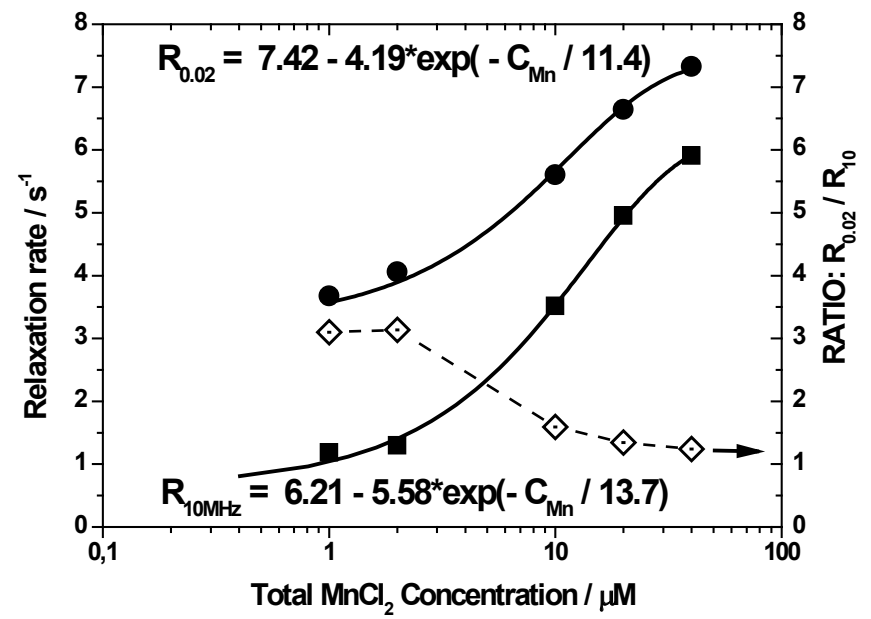

Figure 6: Relaxation rate of aqueous solution of $\mathrm{MnCl}_{2}$ at low $(0.02 \mathrm{MHz})$ and high (10 MHz) Mn-frequencies at various total concentration. The ratio between the relaxation rates at low and high frequencies are displayed in open diamonds $\diamond$.

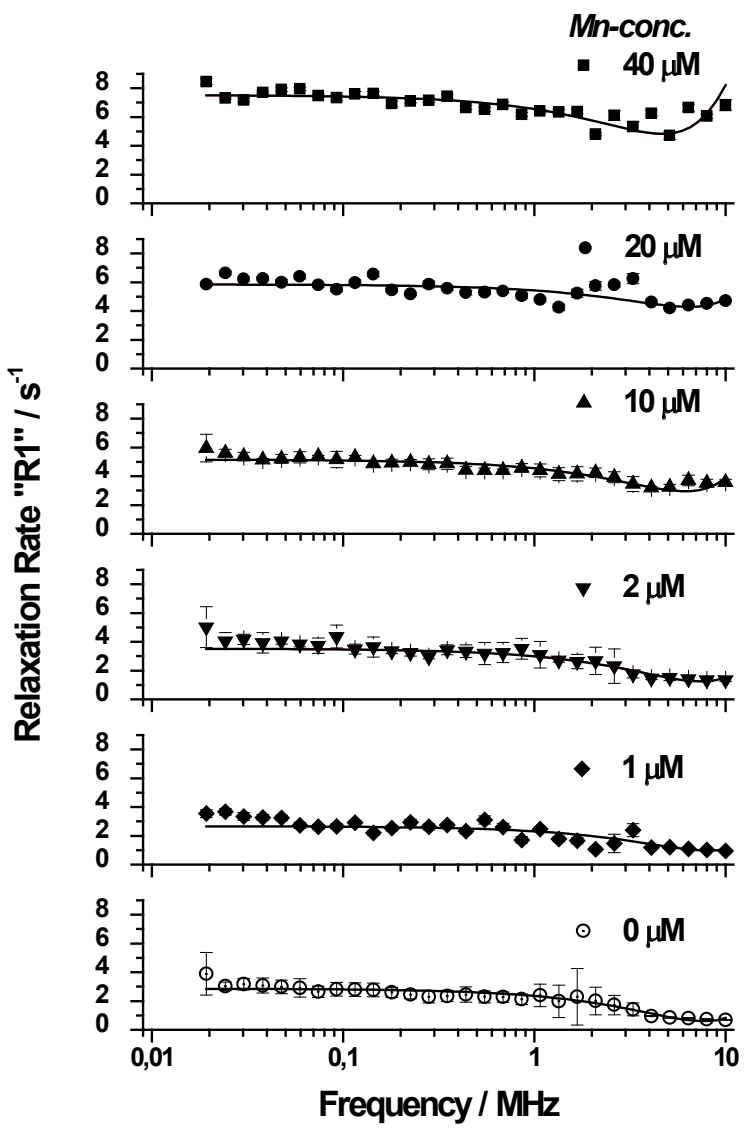

Figure 7: Relaxation rate dispersions of blood plasma with various total Mnconcentrations after adding various volumes of $\mathrm{MnCl}_{2} 0.2 \mathrm{mM}$ solution. The total $\mathrm{Mn}$-concentration in blood-plasma is given by the figures at the right.

$\mathrm{MHz}$ ) from images recorded after relaxation in a field at lower field strength in the range of $0.2-10 \mathrm{mT}(9-426 \mathrm{kHz})$ followed by a higher imaging field at about 0.2-0.5 T. Such sequences of images could be 

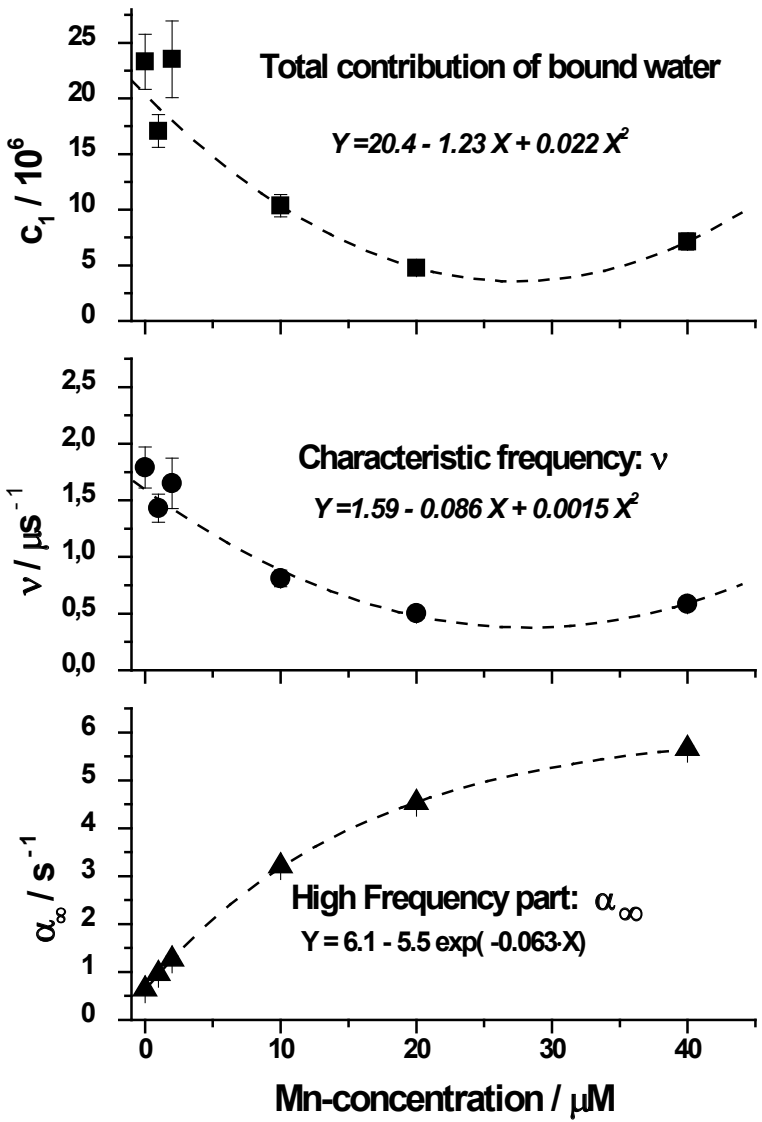

Figure 8: The fitted parameters $\mathrm{c}_{1} ; 1 / \tau_{1} ; \alpha_{\infty}$ of equation (3) at various total concentration of $\mathrm{Mn \mu M}$ in blood plasma or $25^{\circ} \mathrm{C}$

used to study the oxygen status and metabolism of the brain as well as the generation and distribution of reactive oxygen species (ROS). This technique called "Magnetic resonance Relaxation Dispersion Imaging" (MARDI) would be particularly suitable to analyze various neurological diseases such as stroke, MS, Alzheimer's disease as well as brain tumor progression. It might also be suitable for imaging of tumour oxygenation and in vivo ROS distributions in radiation therapy, which could be used in dose planning and for analyzing and optimizing the effect of various radiation therapy regimes.

The use of spatial localized in vivo Field-Cycling NMR-relaxometry was demonstrated already 1992 by Carlson et al. by using a modified clinical whole body system [32]. They applied a Helmholtz coil electromagnet into the aperture of a clinical 64 mT NMR scanner for premagnetization at various fields $(19-109 \mathrm{mT})$. After the electromagnet was turned off, conventional NMR imaging was applied [32].

A similar approach was used by Matter (2006) who developed the electronics for controlling a pre polarized magnetic resonance imaging (PMRI) system [33]. The readout magnet was a Helmholtz coil with $200 \mathrm{mT}$ homogeneous field with an inserted cylindrical polarizing coil magnet. The PMRI technique was demonstrated to be useful for delineating regions of muscle tissue in the extremities of patients by using a pre polarizing field of $0.5 \mathrm{~T}$ and imaging at a much lower field $50 \mathrm{mT}[34]$.

By insertion of a solenoid magnet into the aperture of a MRI device various achievements have been done to realize relaxation dispersion imaging (MARDI) in clinical environments [30,35-38]. Magnetic resonance relaxation dispersion imaging (MARDI) has also been applied for imaging of reactive oxygen radicals and oxygen distribution by using free radical contrast agents [39]. Attempts to develop combined PET and field-cycled MRI the PMRI approach have also been applied by using a pre magnetization field of $1 \mathrm{~T}$ during $1 \mathrm{~s}$ and thereafter an imaging field of $100 \mathrm{mT}$ [40-42].

The slow variation in relaxation rate at higher field strengths $>1.5$ $\mathrm{T}$ was used as a means to reject signal from tissues with enhanced relaxation rate at about $0.5 \mathrm{~T}$. Images with samples of albumin- and buffer-solutions with the albumin-binding Gd-agent Vasovist added, was produced by subtraction of T1-weighted images. For ordinary T1-images, samples with low concentrations of Vasovist in an albumin solution could not be differentiated from samples with higher concentrations of Vasovist in buffer. But with the field cycling technique the images showed high specificity of Gd to albumin [30].

An ordinary NMR imaging device could thus be equipped with an extra solenoid magnet coil, inserted into the aperture and with reversed field adjusting the relaxation magnetic field down to at least $10 \mathrm{mT}$ [38]. The method of FC-imaging involves the weighted subtraction of at least two T1-weighted images. The first imaging sequence as a T1-sequence (or any other suitable sequence) at ordinary high field and the second imaging sequence immediately after a relaxation interval $\left(\tau \approx 3 . \mathrm{T} 1_{\max }\right)$ in decreased B-field $(<10 \mathrm{mT})$. The field cycle imaging technique we propose applies a pre-magnetization at high field about 0.2-0.5 $\mathrm{T}$ for recording a first image. Then a relaxation field at lower field strength $(<10 \mathrm{mT})$ is applied for a short time $(<3 \mathrm{~s})$ by activating an inserted solenoid with a reversed B-field. Immediately after the relaxation interval, a second image is recorded at the original high field strength.

The ultimate goal is aimed to attain a relaxation field of the same magnitude as the earth's magnetic field around $0.05 \mathrm{mT}$, This should allow imaging at normal natural physiological conditions, which might give a completely new dimension to NMR imaging [43-44].

Kimmich et al. [45] showed that the frequency dependence of the proton spin-lattice relaxation times TI (in the laboratory frame) and TIP (in the rotating frame) exhibit similar pattern of field dependence in field cycling experiments. Lamminen et al. [46] have been using T1rho dispersion, or the frequency dependence of $\mathrm{T} 1$ relaxation in the rotating frame, for in vivo muscle tissue characterization and found statistically significant, difference between the relative T1rho dispersion values of normal and diseased muscle tissue. Thus T1rho dispersion measurements and images may be used also for paramagnetic studies.

Recently image-selected volume-localized relaxometry with fast field-cycling in the range of 10-60 $\mathrm{mT}$ has been developed, which offers better signal-to-noise ratio (SNR) and faster acquisition times than image-based techniques. This is achieved by applying a sequence of three selective radiofrequency (RF) pulses in the presence of three orthogonal magnetic field gradients [47]. That technique is very promising for studying the kinetics of radical processes in vivo.

Overhauser Magnetic Resonance Imaging (OMRI) has been used noninvasively for measurement of oxygen concentration by using organic free electron contrast $[39,48]$. MRI devices for the purpose of ESR imaging by the Overhauser effect is first applying low field $(\approx 10$ $\mathrm{mT}$ ) during ESR RF-excitation and then a higher field is applied for NMR imaging [37,49-50]. An Overhauser-enhanced pre-polarized MRI system has been demonstrated for imaging studies of tumor hypoxia and red-ox status to be used as radiotherapy prognostic factors 
Citation: Persson BRR, Malmgren L, Salford LG (2012) Paramagnetic lons Affect Relaxation Rate Dispersion of Blood: Implications for Magnetic Resonance Relaxation Dispersion Imaging. J Bioengineer \& Biomedical Sci 2:105. doi:10.4172/2155-9538.1000105

[51]. The disadvantage with Overhauser Magnetic Resonance Imaging (OMRI) is, however, the extra RF exposure used in the ESR excitation, which is not acquired in pure Field Cycling techniques.

\section{Acknowledgments}

Many thanks are due to Crafoord's Foundation at Lund for generous grant to procure the Field Cycling NMR-spectrometer.Thanks to Professor Bertil Halle, and his post-docs Venu Kandadai, and Vladimir Denisov at the department for Physical chemistry for fruitful discussions, technical support and managing the field-cycle NMR-spectrometer. We also thank the student Christian Dobre for excellent experimental assistance during his summer vacations.

\section{References}

1. Persson B (1982) Medical applications of Nuclear Magnetic Resonce (NMR) (in Swedish). Lund, Sweden: Studentlitteratur.

2. Mallard J, Hutchison JMS, Edelstein W, Foster M, Ling R (1979) Imaging by Nuclear Magnetic-Resonance and its biomedical implications. J Biomed Eng 1: 153-160.

3. Mallard J, Hutchison JM, Edelstein WA, Ling CR, Foster MA, et al. (1980) In vivo n.m.r. imaging in medicine: the Aberdeen approach, both physical and biological. Philos Trans R SocLond B BiolSci 289: 519-533.

4. Gore JC, Kang YS, Schulz RJ (1984) Measurement of Radiation-dose distributions by Nuclear Magnetic-resonance (NMR) Imaging. Physics in Medicine and Biology 29:1189-1197

5. Tokuhiro T, Appleby A, Leghrouz A, Metcalf R, Tokarz R (1996) Proton spinlattice relaxation of water molecules in ferrous-ferric/agarose gel system. J Chem Phys 105: 3761-3769.

6. Brun A, Englund E, Larsson EM, Cronquist S, et al. (1984) Preliminary study of NMR-relaxation times (T1 and T2) and structures of cerebral tumors, oedema and normal tissues. Lund Science Journal.

7. Englund E, Brun A, Larsson EM, Györffy-Wagner Z, Persson B (1986) Tumours of the central nervous system. Proton magnetic resonance relaxation times $T 1$ and T2 and histopathologic correlates. ActaRadiolDiagn (Stockh) 27: 653-659.

8. Englund E, Brun A, Persson B (1987) Correlations between histopathologic white matter changes and proton MR relaxation times in dementia. Alzheimer Dis AssocDisord 1: 156-170.

9. Györffy-Wagner Z, Englund E, Larsson EM, Brun A, Cronqvist S, et al. (1986) Proton magnetic resonance relaxation times $\mathrm{T} 1$ and $\mathrm{T} 2$ related to postmortem interval. An investigation on porcine brain tissue. ActaRadiolDiagn (Stockh) 27 115-118

10. Larsson EM, Englund E, Györffy-Wagner Z, Brun A, Cronqvist S, et al. (1986) Regional differences in the proton magnetic resonance relaxation times $\mathrm{T} 1$ and T2 within the normal human brain. ActaRadiolDiagn (Stockh) 27: 231-234.

11. Olsrud J, Wirestam R, Brockstedt S, Ivarsson K, Holtås S, et al. (1997) Use of the Proton Resonance Frequency Shift (PRF) Method in Phantom Experiments: Application to Thermal Characterisation of Laser Fibres. International Society For Magnetic Resonance in Medicine 5th Sci. Meeting.

12. Olsson M, Brun A, Englund E, Gyöffry-Wagner Z, Larsson EM, et al. (1986) Proton-NMR-Relaxationtimes in vitro in the CNS and parameters affecting the measurements. The Scand Journal of Clin Lab Invest 46:92-93.

13. Olsson M, Persson BRR (1984) A study of the influence of paramagnetic ions on the proton relaxation times T1 and T2. Lund Science Journal.

14. Olsson M, Persson BRR, Salford LG, Schröder U (1985) Superparamagnetic particles as contrast agents in T2 NMR-imaging. Magnetic Resonance Imaging 4: 437-440.

15. Tennvall J, Olsson M, Möller T, Akerman M, Ranstam J, et al. (1987) Thyroid tissue characterization by proton magnetic resonance relaxation time determination. Acta Oncol 26: 27-32

16. Ståhlberg F, Ericsson A, Nordell B, Thomsen C, Henriksen O, et al. (1992) MR imaging, flow and motion (review article). Acta Radiologica 33: 179-200.

17. Wirestam R, Salford LG, Thomsen C, Brockstedt S, Persson BR, et al. (1997) Quantification of low-velocity motion using a navigator-echo supported MR velocity-mapping technique: application to intracranial dynamics in volunteers and patients with brain tumours. MagnReson Imaging 15: 1-11.
18. Winter F, Kimmich R (1982) NMR field-cycling relaxation spectroscopy of bovine serum albumin, muscle tissue, Micrococcus luteus and yeast. $14 \mathrm{~N} 1 \mathrm{H}$ quadrupole dips. BiochimBiophysActa 719: 292-298.

19. Koenig SH, Brown RD, Adams D, Emerson D, Harrison CG (1984) Magneticfield dependence of 1/T1 of protons in tissue. Invest Radiol 19: 76-81.

20. Anoardo E, Galli G, Ferrante G (2001) Fast-field-cycling NMR: Applications and instrumentation. Appl Magn Reson 20: 365-404.

21. Qvist J, Persson E, Mattea C, Halle B (2009) Time scales of water dynamics a biological interfaces: peptides, proteins and cells. Faraday Discuss 141: 131 144

22. Halle B (2009) The physical basis of model-free analysis of NMR relaxation data from proteins and complex fluids. J ChemPhys 131: 22.

23. Halle B (2006) Molecular theory of field-dependent proton spin-lattice relaxation in tissue. MagnReson Med 56: 60-72.

24. Appleby A, Christman EA, Leghrouz A (1987) Imaging of spatial radiation dose distribution in agarose gels using magnetic resonance. Med Phys 14: 382-384.

25. Stelar (1997) Spinnmaster FFC. In: info@stelar.it, editor. 27035 Mede (PV) Italy.

26. Denisov V (1999) Practical Manual for FFC. Lund, Sweden: Condensed Matte Magnetic Resonance Group.

27. Persson E, Halle B (2008) Nanosecond to microsecond protein dynamics probed by magnetic relaxation dispersion of buried water molecules. J Am ChemSoc 130: 1774-1787

28. Persson E, Halle B (2008) Cell water dynamics on multiple time scales ProcNatlAcadSci U S A 105: 6266-6271.

29. Hoogstraten CG, Britt RD (2002) Water counting: quantitating the hydration level of paramagnetic metal ions bound to nucleotides and nucleic acids. RNA 8: 252-260.

30. Alford JK, Rutt BK, Scholl TJ, Handler WB, Chronik BA (2009) Delta relaxation enhanced MR: improving activation-specificity of molecular probes through R1 dispersion imaging. MagnReson Med 61: 796-802

31. Bertin A, Steibel J, Michou-Gallani Al, Gallani JL, Felder-Flesch D (2009) Development of a dendritic manganese-enhanced magnetic resonance imaging (MEMRI) contrast agent: synthesis, toxicity (in vitro) and relaxivity (in vitro, in vivo) studies. Bioconjug Chem 20: 760-767.

32. Carlson JW, Goldhaber DM, Brito A, Kaufman L (1992) MR relaxometry imaging. Work in progress. Radiology 184: 635-639.

33. Matter NI (2006) Electromagnet Control ad effecient imaging in prepolarized MRI (PhD Thesis). Stanford: Stanford University.

34. Ungersma SE, Matter NI, Hardy JW, Venook RD, Macovski A, et al. (2006 Magnetic resonance imaging with T-1 dispersion contrast. Magn Reson Med 55: 1362-1371

35. Macovski A (2009) MRI: a charmed past and an exciting future. J MagnReson Imaging 30: 919-923.

36. Lurie DJ, Li H, Petryakov S, Zweier JL (2002) Development of a PEDRI freeradical imager using a $0.38 \mathrm{~T}$ clinical MRI system. MagnReson Med 47: 181 186

37. Lurie DJ, Davies GR, Foster MA, Hutchison JM (2005) Field-cycled PEDR imaging of free radicals with detection at $450 \mathrm{mT}$. MagnReson Imaging 23 : 175-181.

38. Alford JK, Scholl TJ, Handler WB, Chronik BA (2009) Design and Construction of a Prototype High-Power B0 Insert Coil for Field-Cycled Imaging in Superconducting MRI Systems. Concepts Magn Reson 35: 1-10.

39. Golman K, Petersson JS, Ardenkjaer-Larsen JH, Leunbach I, Wistrand LG, et al. (2000) Dynamic in vivo oxymetry using Overhauser enhanced MR imaging. J Magn Reson Imaging 12: 929-938.

40. Peng H, Handler WB, Scholl TJ, Simpson PJ, Chronik BA (2010) Proof-ofprinciple study of a small animal PET/field-cycled MRI combined system using conventional PMT technology. Nuclear Instruments \& Methods in Physics Research Section a-Accelerators Spectrometers Detectors and Associated Equipment 612: 412-420.

41. Gilbert KM, Handler WB, Scholl TJ, Odegaard JW, Chronik BA (2006) Design of 
Citation: Persson BRR, Malmgren L, Salford LG (2012) Paramagnetic lons Affect Relaxation Rate Dispersion of Blood: Implications for Magnetic Resonance Relaxation Dispersion Imaging. J Bioengineer \& Biomedical Sci 2:105. doi:10.4172/2155-9538.1000105

Page 8 of 8

field-cycled magnetic resonance systems for small animal imaging. Phys Med Biol 51: 2825-2841.

42. Gilbert KM, Scholl TJ, Handler WB, Alford JK, Chronik BA (2009) Evaluation of a positron emission tomography (PET)-compatible field-cycled MRI (FCMRI) scanner. MagnReson Med 62: 1017-1025.

43. Trahms L, Burghoff M (2010) NMR at very low fields. Magnetic Resonance Imaging 28: 1244-1250.

44. Packard ME, Varian RH (1954) Free nuclear induction in the Earth's magnetic field Phys Rev 93v.

45. Kimmich R, Weber HW (1993) Nuclear magnetic-relaxation spectroscopy of polymers and anomalous segment diffusion - reorientations mediated by translational displacements. J Chem Phys 98: 5847-5854

46. Lamminen AE, Tanttu JI, Sepponen RE, Pinko H, Korhola OA (1993) T1 rho dispersion imaging of diseased muscle tissue. Br J Radiol 66: 783-787.
47. Pine KJ, Davies GR, Lurie DJ (2010) Field-cycling NMR relaxometry with spatial selection. Magn Reson Med 63: 1698-1702.

48. Ardenkjaer-Larsen JH, Laursen I, Leunbach I, Ehnholm G, Wistrand LG, et al (1998) EPR and DNP properties of certain novel single electron contrast agents intended for oximetric imaging. J MagnReson 133: 1-12.

49. Lurie DJ, Bussell DM, Bell LH, Mallard JR (1988) Proton Electron Double Magnetic-Resonance Imaging of free-radical solutions. Journal of Magnetic Resonance 76: 366-370.

50. Shet K, Caia GL, Kesselring E, Samouilov A, Petryakov S, et al. (2010) A nove variable field system for field-cycled dynamic nuclear polarization spectroscopy. $J$ Magn Reson 205: 202-208.

51. Ahn KH, Scott G, Stang P, Conolly S, Hristov D (2011) Multiparametric Imaging of Tumor Oxygenation, Redox Status, and Anatomical Structure Using Overhauser-Enhanced MRI-Prepolarized MRI System. Magn Reson Med 65: 1416-22. 